DOI: $10.21608 / z v j z .2017 .7865$.

\title{
Investigation of Cross Neutralization of Egyptian Variant 2 among both Classic and
} Variant Vaccinal Infectious Bronchitis Viruses

Ekram S. Mahmoud, Nermeen M. El-Sayed, Ghada M. El-Sadek*, Hayam F. Sayed, Lamiaa M. Omar and Mansour H. Abdel Baky Central Laboratory for Evaluation of Veterinary Biologics, Abbasia, Cairo

Article History: Received: 15/6/2017 Received in revised form: 22/10/2017 Accepted: 15/11/2017

\begin{abstract}
Infectious Bronchitis Virus (IBV) is considered an important virus which may cause major losses in the poultry industry. One of the most important and effective tool that control the infection spread is the vaccination strategy. The present study was undertaken to determine the antigenic relationship between the currently used IBVs, classic and variant vaccinal strains, and the dominating Egyptian variant-2, IBV which could be relatively reflecting the quality of such vaccine. The recommended doses of the monovalent live IBV vaccines of Ma5, H120, 4/91 \& CR88, and bivalent vaccine of H120-D274 were administrated via the eye-drop route in groups of 2-week-old SPF-chickens. Three weeks after vaccination, immunized and control chickens were bled, and serum samples were collected. Sera were tested individually for measuring the IBV-Haemagglutination Inhibiting (HI) antibodies against each of IBV-haemagglutinating antigen prepared from the reference classic M41 strain and the Egyptian variant.2 strain (Egy/12/2b spike protein), and IBV- neutralizing antibodies against the Egyptian variant-2 strain. The chicken groups vaccinated with the commercial live vaccines of strains Ma5, H120, 4/91, CR88 and H120-D274 of IBV respectively developed mean serum HI-antibody titers of 6.8, 6.5, 4.9, 5.0 and $5.5 \log _{2}$ with the reference classic strain M41-HA antigen, and 3.0, 3.0, 4.4, 4.0, and $4.6 \log _{2}$ with the Egyptian variant. 2 strain-HA antigen. However, the obtained results revealed utility of VN test more than $\mathrm{HI}$ test for assessment of the antigenic relatedness between the vaccinal and challenge strains of IBV as well as testing quality of different commercial live IBV vaccines using the sera of vaccinated chickens against the field strain(s) matched with the homologous strain(s); the antigenic relatedness $\left(r_{1}\right)$ between the dominating Egyptian variant-2 strain, and the vaccinal strains, CR88, D274-H120 and H120 of IBV were 33\%, 55\% and 17\% respectively.
\end{abstract}

Keywords: Infectious Bronchitis, Classic, Egyptian Variant 2, Cross Neutralization.

\section{Introduction}

In Egypt, Infectious Bronchitis (IB) is an important contagious viral disease which threatens continuously the growing chicks coinfected with other respiratory pathogens such as low pathogenic avian influenza virus, subtype H9N2, Newcastle disease virus, pathogenic Escherichia coli, and mycoplasma species $[1,2]$. The causative avian coronavirus is an enveloped single stranded positive sense RNA virus. The virion structural proteins are nucleocapsid (N), membrane glycoprotein $(\mathrm{M})$, small enveloped protein $(\mathrm{E})$, and the surface glycoprotein (S) which has characteristic cub-shaped spikes of about 20 $\mathrm{nm}$ in length and compromises two subunits, $\mathrm{S} 1$ and S2 [3,4]. The epitopes responsible for induction of the IBV serotype-specific antibodies are thought to be located in the hyper-variable region of the S1 protein [3,5].
The IBV-haemagglutination inhibiting (HI) and most virus neutralizing (VN) antibodies are directed against $\mathrm{S} 1$ glycoprotein, and the unique amino acid sequences on this glycoprotein determine the IBV serotype [6,7]. The IBV serotypes, genotypes and protectotypes are determined depending on the cross VN or HI tests, comparative nucleotides sequencing of $\mathrm{S} 1$ and its deduced amino acids sequence of the spike glycoprotein of the virus, and cross protection test [8-11]. Variant strain of IBV is a virus that was changed antigenically or genetically to the point where it can be identified as different or unique from the others. The VN test is the preferred method for serological typing of different strains or isolates of IBV because $\mathrm{HI}$ test lacks some specificity, while in general the IBVneutralizing or haemaggltination inhibiting antibody titers in sera of the vaccinated 
chickens are good indicators of responses to vaccination and immune status [12].

The vaccination regime using the vaccine(s) of suitable protectotype strain(s) that are compatible at least with the predominant circulating virus is one of the effective tools that could control IB- infection in chickens. In Egypt, vaccines of classic IBV Mass strains, and European variant strains are registered and used, while variant-2 of IB virus have been isolated routinely from broiler chick flocks suffering from respiratory manifestations and high mortalities [1,2]. The full length $\mathrm{S} 1$ gene nucleotide sequence and its deduced amino acids homology percentages of the Egyptian variants of 2012 against the widely used vaccinal strains, H120, Ma5, CR88, D274 and $4 / 91$ showed low correlation from $77 \%$ to 85 $\%$ [13].

In the current work, the antigenic relationship between the currently used IBV, classic vaccinal strains (H120 and Ma5) and variant vaccinal strains (4/91, CR88, and D247), and the dominating Egyptian variant-2 of IBV was studied throughout application of $\mathrm{HI}$ test and $\mathrm{VN}$ test in assessment of the protective and serotype identifying antibodies in sera of chickens immunized with different commercial live IBV vaccines.

\section{Material and Methods}

\section{Specific pathogen free - embryonated chicken eggs (SPF-ECE)}

Two hundred SPF-ECEs were purchased from SPF-ECEs Production Farm, Koum Osheim, El-Fayoum, Egypt and used for propagation of IBV and conduction of virus neutralization test.

\section{SPF chicks}

One hundred and twenty-two-weeks-old SPF-chicks were purchased from SPF- Farm, Koum Osheim-, El-Fayoum, Egypt and housed in separate negative pressure filtered air isolators in isolation building at the Central Laboratory for Evaluation of Veterinary Biologics (CLEVB), Abbasia, Cairo and were used for evaluation of the immunogenicity of each of the five different commercial live IBV vaccines.

\section{Vaccines}

Potent valid commercial monovalent live vaccines of classic strains (H120 and MA5), variant strains (4/91 and CR88) and bivalent vaccine (of classic strain $\mathrm{H} 120$ with variant strain D274) of a titer $8.5 \mathrm{EID}_{50} / \mathrm{ml}$ for each vaccine were used to vaccinate different groups of SPF- chicks.

\section{Viruses}

Embryonated chicken egg-adapted Classic M41 strain of IBV was supplied by the Department of Animal Science and Agricultural Biochemistry, University of Delware, New York, USA. While, the Egyptian variant-2 strain of IBV (strain $\mathrm{Eg} / 12 / 2 \mathrm{~b}$ spike protein of the gene bank accession No. JQ839287) was supplied by the National Lab for Quality Control of Poultry (NLQP), Giza, Egypt. The viruses were propagated and tittered in 9 day-old SPF-ECEs and reviewed for identity, purity and pathogenicity by the Central Lab for Evaluation of Veterinary Biologics (CLEVB), Cairo, Egypt. These strains were used for preparation of IBV-HA-antigens, and conduction of virus neutralization test.

\section{HA- Antigen Preparation}

Four HA unit antigens of classical strain M41 of IBV and Egyptian variant-2 of IBV were prepared [14] as follows: Each virus stock of approximately $5.5 \log _{10}$ EID $_{50} / 0.1$ $\mathrm{mL}$ was diluted $1 / 10$ in sterile Phosphate Buffered Saline (PBS) of $\mathrm{pH} 7.2$ and inoculated into 9-10 day-old SPF-ECEs via the Chorioallantoic sac (CAS) with $0.1 \mathrm{~mL} / \mathrm{each}$. At 72 hours after incubation, Amnio-allantoic fluid (AAF) was harvested from chilled embryos, and then clarified by centrifugation at 3000 r.p.m for 30 minutes, after which the pellet was discarded. Fresh $2 \%$ of bovine trypsin (manufactured by Sigma Chemical Company, St. Louis, Mo, USA) in PBS, pH 7.2 was prepared, then mixed with the clarified infected AAF at ratio $2 \mathrm{~V}: 1 \mathrm{~V}$ and was held at $37^{\circ} \mathrm{C}$ in water bath for $30 \mathrm{~min}$, then placed at $4^{\circ} \mathrm{C}$ for $5 \mathrm{~min}$. The prepared HA antigens were titrated by HA test to determine HA units of each, and stored at $4^{\circ} \mathrm{C}$. The trypsinized AAF was checked for IBV presence by clear and consistent agglutination of chicken RBCs within 5 min of incubation at $37^{\circ} \mathrm{C}$ [15]. 


\section{Haemagglutination Haemagglutination Inhibition (HI) tests}

$\mathrm{HA} / \mathrm{HI}$ tests were performed to determine HA units in the prepared antigens, and assay $\mathrm{HI}$-antibody titers in serum samples of the vaccinated chickens [16].

\section{Experimental Design}

Each of the five commercial live IBV vaccines of strains MA5, H120, 4/91, CR88, and H120-D274 was administrated via the eyedrop route in each of twenty SPF- chicks of two weeks old with the recommended dose titer for each vaccine (not less than $3.5 \log _{10}$ $\left.E D_{50}\right)$. Also, twenty SPF- chickens of the same age were maintained as negative control group. Three weeks later, ten vaccinated chicks and ten control chicks were bled, and serum samples were collected.

Collected sera were inactivated by heating at $56^{\circ} \mathrm{C}$ in a water bath for 30 minutes, and tested individually by assay IBVHaemagglutination Inhibiting (HI) antibody titers against each of HA-antigens prepared from the Mass strain and the Egyptian variant2 strain, and measure IBV-neutralizing antibody indices against the Egyptian variant-2 strain.

Geometric mean titers (GMT) of HIantibodies and mean indices of $\mathrm{VN}$-antibodies in sera of each group of vaccinated chickens, and group of unvaccinated chicken were recorded and calculated [17].

Percentages of antigenic relatedness were estimated following the statistical method previously described [18]. The relatedness $\left(r_{1}\right)$ is the ratio of the mean neutralization index with the heterologous virus (Egyptian variant.2 virus) to the minimum required mean neutralization index with the homologous virus multiplied with 100 .

\section{Neutralization test (NT)}

Alpha method of VN was carried out to measure IBV-neutralizing antibodies in serum samples of vaccinated chickens against the Egyptian variant 2 strain of IBV.

Variable ten-fold dilutions of prepared IB virus, and a $1 / 5$ dilution of the test and control serum samples were prepared in PBS, $\mathrm{pH}$ 6.87.2. Equal volumes of the diluted serum and virus were mixed and incubated at room temperature for 2 hours, and then each mixture was inoculated into nine-day-old SFP-ECEs via allantoic sac route as $0.2 \mathrm{~mL} / \mathrm{egg}$. The virus alone was titrated parallel. EID $_{50}$ of each of the virus-serum mixtures and the virus alone was calculated [19]. The results were expressed as a neutralization index (NI) that represent the Log difference in the EID $_{50}$ of virus alone and that of the virus-serum mixture [16].

\section{Results and Discussion}

Infectious Bronchitis Virus is a positivesense, single stranded RNA virus. Different genotypes of IBV have been identified allover the world [1,2]. Although the routine and continuous vaccination of chicken with IBV, outbreaks still frequently occur in the field due to the emergence of different variant serotypes beside the classical subtypes. The present study was done to determine the antigenic relationship between the strains of the currently used commercial live vaccines of IBV and the circulating IB virus as a guide for the quality of such vaccines.

The chicken groups vaccinated with $\mathrm{EID}_{50^{-}}$ potency valid commercial live IBV vaccines of strains MA5, H120, 4/91, CR88 and H120D274 respectively developed mean serum HIantibody titers of $6.8,6.5,4.9,5.0$ and $5.5 \log _{2}$ against the reference classic strain M41-HA antigen which might be represented the circulating classic IBV, and 3.0, 3.0, 4.4, 4.0, and $4.6 \log _{2}$ by the Egyptian variant-2 strainHA antigen (Table 1). Chicken groups vaccinated with IBV vaccines of strains 4/91, H120-D274 and H120, respectively, developed mean serum neutralizing antibody indices of $1.5,2.5$ and 0.75 by the Egyptian variant.2 strain (Table 2).

These results signify that firstly; monovalent vaccines containing strains MA5 and $\mathrm{H} 120$ of the Massachusetts serotype, which is used frequently in Egypt, succeeded to induce satisfactory serum antibody titers (6.8 $\log _{2}$ and $6.5 \log _{2}$ respectively) against the strain M41-HA antigen (the mean titers were more than $6.0 \log _{2}$ ) which exhibited less cross HI reaction by the Egyptian Variant2 strainHA antigen (the mean titers were $3.0 \log _{2}$ ) 
The appreciated positive IBV-HI antibody titer is not less than $4 \log _{2}$ and IBV-N antibody indices is not less than $1.5 \log _{10}$, and the mean NI of 4.5 is the minimum acceptable level of IBV neutralizing antibodies in sera of chickens vaccinated with live vaccine as tested against the homologous strain, and the heterologous strain give a mean NI not less than 1.5 [16].

It was found that there was little cross HI reaction by the Egyptian variant-2 strain-HA antigen (the mean titers were $3.0 \quad \log _{2}$ ), secondly; sera of the chickens vaccinated with monovalent vaccines of the variant strains 4/91 and CR88 of IBV exhibited a moderate cross HI reaction against the strain M41- HA antigen with mean titer range of 4.9-5.0 $\log _{2}$ and low cross $\mathrm{HI}$ reaction by the Egyptian variant-2 strain - HA antigen with mean titer range of $4.4-4.0 \quad \log _{2}$. Thirdly; bivalent vaccine of H120-D274 strains initiated the chickens to develop serum HI-antibodies which cross reacted with the strain M41-HA antigen with mean titer of $5.5 \log _{2}$, and the Egyptian variant.2 strain-HA antigen with mean titer of $4.6 \log _{2}$, and fourthly; The antigenic relatedness $\left(r_{1}\right)$ between strains of the test vaccines 4/91, H120-D274 and H120 and the Egyptian variant. 2 strain of IBV were $33 \%, 55 \%$ and $17 \%$ (negative), respectively, as estimated by dividing mean virus neutralization indices in sera of each group of the vaccinated chickens by 4.5 [16]. Isolates with $\mathrm{r}_{1}$ value between $50 \%$ and $100 \%$ were considered to be antigenically related [20]. Variable cross reactions were found in the HI test, and the differences between the strains were less clear in the HI test [8].

In this respect, different researchers concluded that HI test is an IBV serotype specific test, and NT is the gold standard test for the detection of IBV serotype specific antibodies in sera of chickens after single vaccination [1,2,11,21-23]. The specificity of the $\mathrm{HI}$ test is considered to be lower than that of the NT. Detection of IBV-HI and-VN antibodies by the homologous strain in sera of chickens vaccinated with the live vaccine is far more suited to check the take of vaccine (immunogenicity) rather than being used challenge test (efficacy).

Table 1: IBV-HI antibody titers in SPF-chickens vaccinated with classic and/or variant commercial live IBVvaccines

\begin{tabular}{lcc}
\hline \multirow{2}{*}{ Vaccines } & \multicolumn{2}{c}{ Mean of IBV HI titer $\left(\mathbf{l o g}_{2}\right)$ using HA antigens } \\
\cline { 2 - 3 } & Classical IBV strain M41 & Egyptian IBV variant 2 strain \\
\hline MA5 & 6.8 & 3.0 \\
4/91 & 4.9 & 4.4 \\
CR88 & 5.0 & 4.0 \\
H120-D274 & 5.5 & 4.6 \\
H120 & 6.5 & 3.0 \\
\hline
\end{tabular}

Table 2: IBV- neutralizing antibody indices in SPF-chickens vaccinated with a commercial live IBV-vaccines using Egyptian variant-2 strain

\begin{tabular}{lc}
\hline Used vaccines & Mean IBV neutralizing index \\
\hline 4/91 & 1.5 \\
H120-D274 & 2.5 \\
H120 & 0.75 \\
\hline
\end{tabular}

\section{Conclusion}

In conclusion, the obtained results demonstrate the relative differences between $\mathrm{HI}$ test and VN test for detection and titration of serum IBV serotype specific antibodies which provoked by vaccination of SPFchickens with one dose of the commercial live IBV vaccine, and display a low antigenic relatedness between the currently used IBV vaccines and the dominating Egyptian variant2 IBV. However, bivalent (H120-D274) vaccine is more reliable in antigenic relatedness to commonly circulating varian 2 IB virus.

\section{Conflict of interest}

The authors declare no conflict of interest. 


\section{References}

[1] Abdel-Moneim, A.S., Afifi, M.A. and ElKady, M.F. (2012): Emergence of a novel genotype of avian infectious bronchitis virus in Egypt. Arch Virol, 157(12): 24532457.

[2] Fathy, R.R.; El Boraay, I.M.; El Shorbagy, M.A. and Susan, S. E. (2015): A survey on presence of new strains of infectious bronchitis virus in some chicken farms of Egyptian Delta provinces during 2014. Benha Vet Med J, 28 (2): 248-262.

[3] Cavanagh, D., Davis, P.J. and Mockett, A.P.A. (1988): Amino acids within hypervariable region 1 of avian coronavirus IBV (Massachusetts serotype) spike glycoprotein are associated with neutralization epitopes. Virus Res, 11(2), 141-150.

[4] Cavanagh, D. and Naqi, S.A. (1997): Infectious Bronchitis. In B.W. Calnek, H.J. Barnes, C.W. Beard, L.R. McDougald and Y.M. Saif (Eds.), Iowa University Press, Ames, USA, pp. 511-526.

[5] Kock, G., Kant, A., Cook, J.K.A. and Cavanagh, D. (1991): Epitopes of neutralizing antibodies are localized within three regions of the S1 spike protein of infectious bronchitis virus. In E.F. Kaleta and U. Heffels-Redmann (Eds): Proceeding of the II International Symposium on Infectious Bronchitis (pp. 154-161). Rauischholzlausen, Germany.

[6] Cavanagh, D., Darbyshire, J.H., Davis, P. and Peters, R.W. (1984): Induction of humoral neutralizing and haemagglutination-inhibiting antibody by the spike protein of avian infectious bronchitis virus. Avian Pathol, 13(3):573583.

[7] Butcher, G.D., Shapiro, D.P. and Miles, R,D. (2011): Infectious bronchitis virus: Classical and variant strains. One of a series of the Veterinary Medicine-Large Animal Clinical Sciences Department, Florida Cooperative Extension Service, IFAS 2011; VM127.

[8] Cook, J. K., Brown, A.J. and Bracewell, C.D. (1987): Comparison of the haemagglutination inhibition test and the serum neutralization test in tracheal organ cultures for typing infectious bronchitis virus strains. Avian Pathol, 16(3), 505-511.

[9] Cavanagh, D., Davis, P.J., Cook, J.K., Li, D., Kant, A. and Koch, G. (1992): Location of the amino acid differences in the S1 spike glycoprotein subunit of closely related serotypes of infectious bronchitis virus. Avian Pathol, 21(1), 33-43.

[10] Cavanagh, D., Ellis, M.M. and Cook, J.K. (1997): Relation between sequence variation in the $\mathrm{S} 1$ spike protein of infectious bronchitis virus and the extent of cross-protection in vivo. Avian Pathol, 26(1), 63-74.

[11] De Wit, J.J., Mekkes, D.R., Kouwenhoven B. and Verheidjden, H.M. (1997): Sensitivity and specificity of serological tests for infectious bronchitis virus antibodies in broilers. Avian Pathol, 26(1): 105-118.

[12] Ignjatovic, J. and Sapats, S. (2000): Avian infectious bronchitis virus. Rev Sci Tech Off Int Epiz, 19 (2), 493-508.

[13] Samir, M., Selim, A., Arfa, A., Khaleil, S., Hagag, N., Samir, A. and Hasan, M. (2014): molecular diversity between field isolates and vaccinal strains of avian infectious bronchitis virus. Glob Vet, 13 (5): 820-824.

[14] Mahmood, M.S., Siddique, H., Hussain, I. and Khan, A. (2004): Trypsin-induced haemagglutination assay for the detection of infectious bronchitis virus. Pak Vet J,24 (2):54-57

[15] Munir, S., Hussain, M., Farooq, U., ZabidUllah, Jamal, Q., Afreen, M., Bano, K., and Anees, M., (2012): Quantification of antibodies against poultry haemagglutinating viruses by haemagglutination inhibition test in Lahore. Afr J Microbiol Res, 6 (21): 4614-4619.

[16] OIE, Terrestrial Manual (2016): Manual of Diagnostic Tests and Vaccines for Terrestrial Animals, Avian Infectious Bronchitis, Chapter 2.3.2. 
[17] Brugh, M.A. (1978): Simple method for recording and analyzing serological data. Avian Dis, 22: (2) 362-365.

[18] Archetti, I. and Housfall, F.L. (1950): Persistence antigenic variation of influenza A viruses after incomplete neutralization in ovo with heterologous immune serum. J Exp Med, 92(5), 441462.

[19] Reed, L.J., and Muench, H. (1938): A simple method of estimating fifty percent end point. Am J Epidemiol, 27(3), 493497.

[20] Gelb, J. Jr., Keeler, C.L.Jr., Nix, W.A., Rosengerger, J.K. and Cloud, S.S. (1997): Antigenic and S-1 genomic characterization of the Delawere variant serotype of IBV. Avian Dis, 41(3), 661669.
[21] King, D.J. and Hopkins, S.R. (1983): Evaluation of HaemagglutinationInhibition test for measuring the response of chickens to avian infectious bronchitis virus vaccination. Avian Dis, 27(1), 100112.

[22] Lashgari, M.S. and Newman, J.A. (1984): Serological comparison and antigenic relationships of seven serotypes of infectious bronchitis virus using the haemagglutination-inhibition test. Avian Dis, 28(2): 435-443.

[23] Zanaty, A., Arafa, A., Hagag, N. and ElKady, M. (2016): Genotyping and pathotyping of diversified strains of infectious bronchitis viruses circulating in Egypt. World J Virol, 5(3): 125-134.

\footnotetext{
الملخص العربى العيى

استقصاء التعادل المتبادل للعترة المصرية المتابينة_ب لكل من العترة التقليدية وعترة اللقاح المتابينة لفيروس الالتهاب

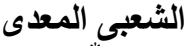

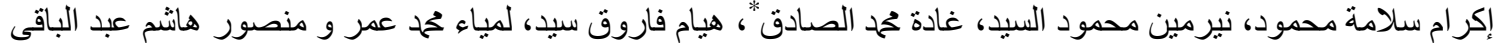

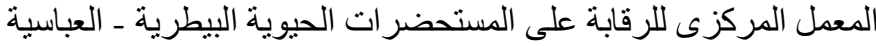

يعد فيروس الالتهاب الثعبي من اهم الفيروسات التي تسبب خسائر جسيمة في صناعة الدو اجن وتعتبر استر اتيجية التحصين

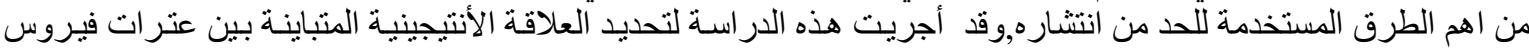

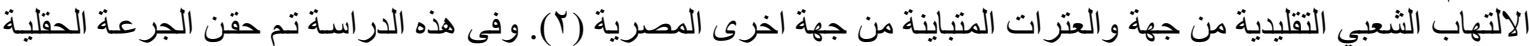
من لقاحات الالتهاب الثعبي الحيةCR88, 4/91, H120, MA5 (كلقاحات أحادية) بالإضـافة إلى اللى اللقاح (D274-H120)

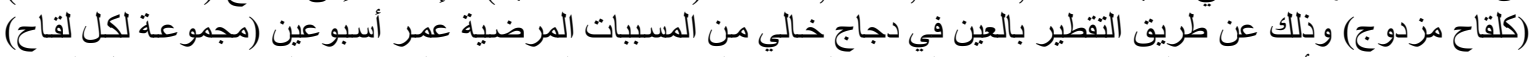

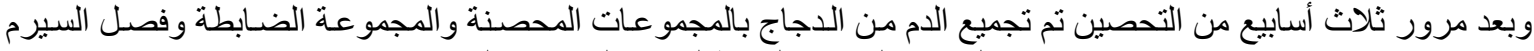

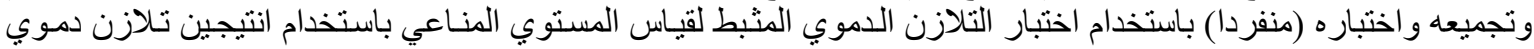

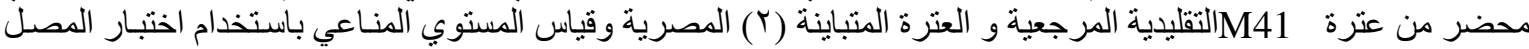

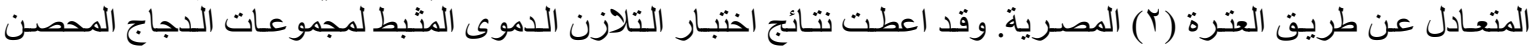

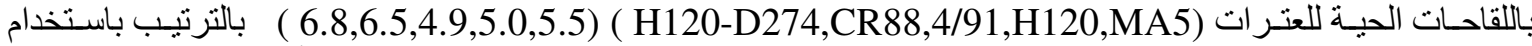

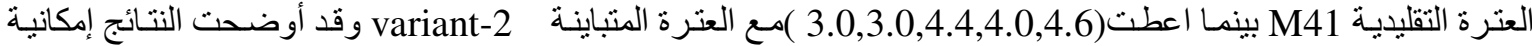

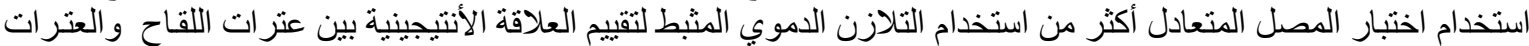

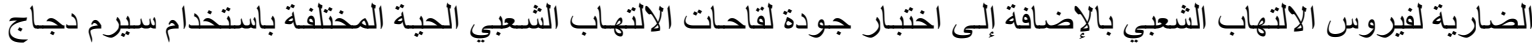

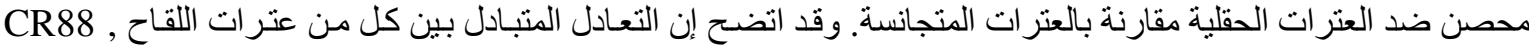

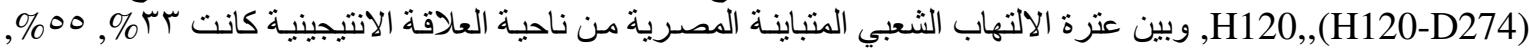

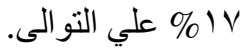

